\title{
Proteostasis and RNA Binding Proteins in Synaptic Plasticity and in the Pathogenesis of Neuropsychiatric Disorders
}

\author{
Matthew E. Klein, ${ }^{1}$ Hannah Monday, ${ }^{1}$ and Bryen A. Jordan ${ }^{1,2}$ \\ ${ }^{1}$ Dominick P. Purpura Department of Neuroscience, Albert Einstein College of Medicine, 1300 Morris Park Avenue, \\ Bronx, NY 10461, USA \\ ${ }^{2}$ Department of Psychiatry and Behavioral Sciences, Albert Einstein College of Medicine, 1300 Morris Park Avenue, \\ Bronx, NY 10461, USA \\ Correspondence should be addressed to Bryen A. Jordan; bryen.jordan@einstein.yu.edu
}

Received 6 July 2015; Accepted 30 September 2015

Academic Editor: Christian Wozny

Copyright (C) 2016 Matthew E. Klein et al. This is an open access article distributed under the Creative Commons Attribution License, which permits unrestricted use, distribution, and reproduction in any medium, provided the original work is properly cited.

\begin{abstract}
Decades of research have demonstrated that rapid alterations in protein abundance are required for synaptic plasticity, a cellular correlate for learning and memory. Control of protein abundance, known as proteostasis, is achieved across a complex neuronal morphology that includes a tortuous axon as well as an extensive dendritic arbor supporting thousands of individual synaptic compartments. To regulate the spatiotemporal synthesis of proteins, neurons must efficiently coordinate the transport and metabolism of mRNAs. Among multiple levels of regulation, transacting RNA binding proteins (RBPs) control proteostasis by binding to mRNAs and mediating their transport and translation in response to synaptic activity. In addition to synthesis, protein degradation must be carefully balanced for optimal proteostasis, as deviations resulting in excess or insufficient abundance of key synaptic factors produce pathologies. As such, mutations in components of the proteasomal or translational machinery, including RBPs, have been linked to the pathogenesis of neurological disorders such as Fragile X Syndrome (FXS), Fragile X Tremor Ataxia Syndrome (FXTAS), and Autism Spectrum Disorders (ASD). In this review, we summarize recent scientific findings, highlight ongoing questions, and link basic molecular mechanisms to the pathogenesis of common neuropsychiatric disorders.
\end{abstract}

\section{Ribonucleoproteins and RBPs}

The majority of cytoplasmic mRNAs in neurons are associated with RBPs and other accessory proteins as part of large macromolecular complexes termed ribonucleoprotein (RNP) granules [1]. Granules are diverse in composition and function, mediating many aspects of posttranscriptional RNA regulation including cellular transport, protection from nucleases, and translational control [2-4]. The modular domain structure of RBPs facilitates granule formation and enables auxiliary interactions with other factors necessary to ensure precise localization and metabolism of mRNA cargos [5]. Recent evidence suggests that only one mRNA is present per RNP granule [6-9]. This stoichiometry may be achieved through cotranscriptional packaging of the RNP complex as many RBPs contain nuclear localization sequences and undergo nucleocytoplasmic transport [10, 11]. Following transcription, RBPs are thought to spontaneously couple to mRNA targets to facilitate processing of pre-mRNAs through splicing, editing, polyadenylation, and granule formation (Figure 1). In addition, many RBPs contain prion-like low complexity sequences that may allow for spontaneous self-aggregation. Thus, cargo mRNAs could act as scaffolds/nucleators for aggregation by recruiting and increasing the local concentration of RBPs to catalyze spontaneous granule formation [12]. Low complexity sequences may also promote heteroaggregation of accessory proteins into granules and allow for the dynamic disassembly and reformation of RNP granules in response to synaptic activity $[7,12,13]$.

\section{RBPs and Neuronal Dendritic Targeting}

The control of RNA distribution is a fundamental mechanism underlying localized expression of proteins [14]. This is especially pertinent among the intricate dendritic arbors of 


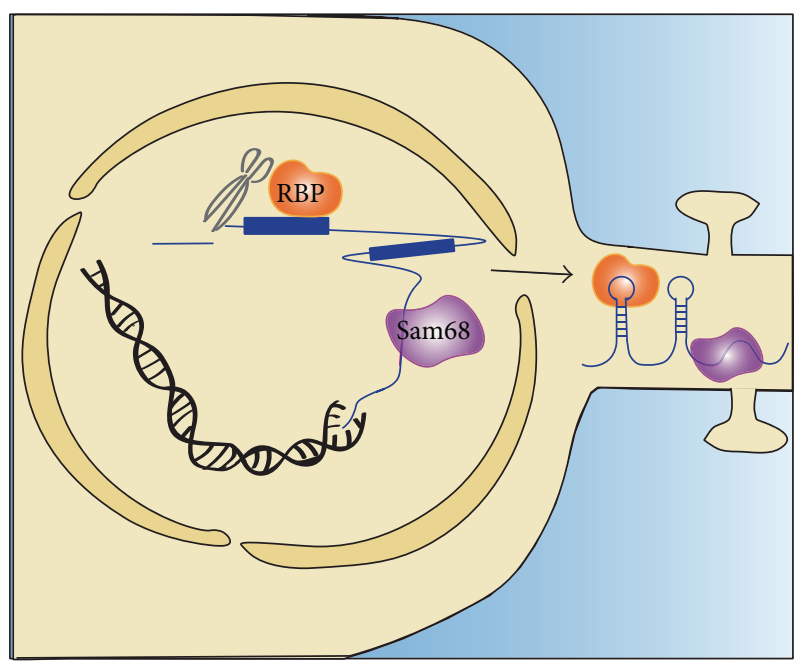

(a)

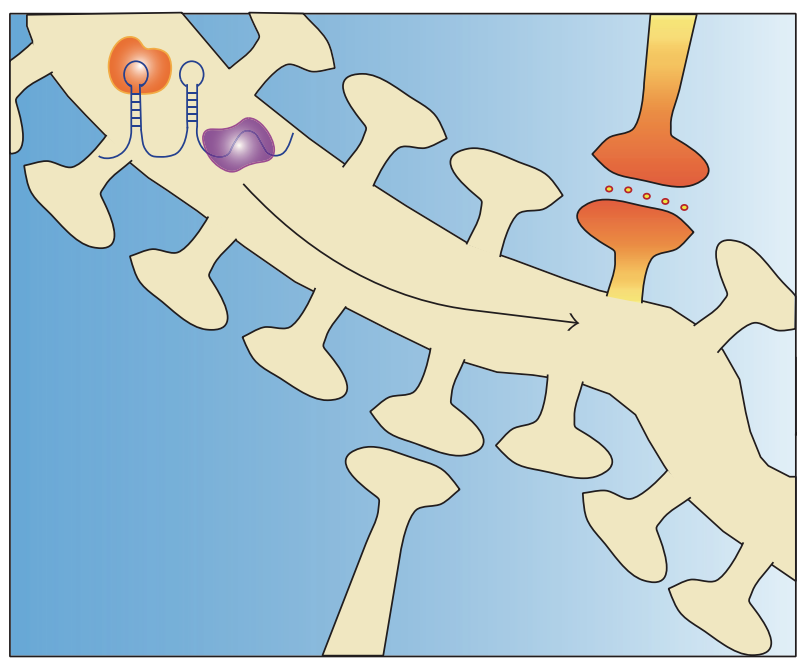

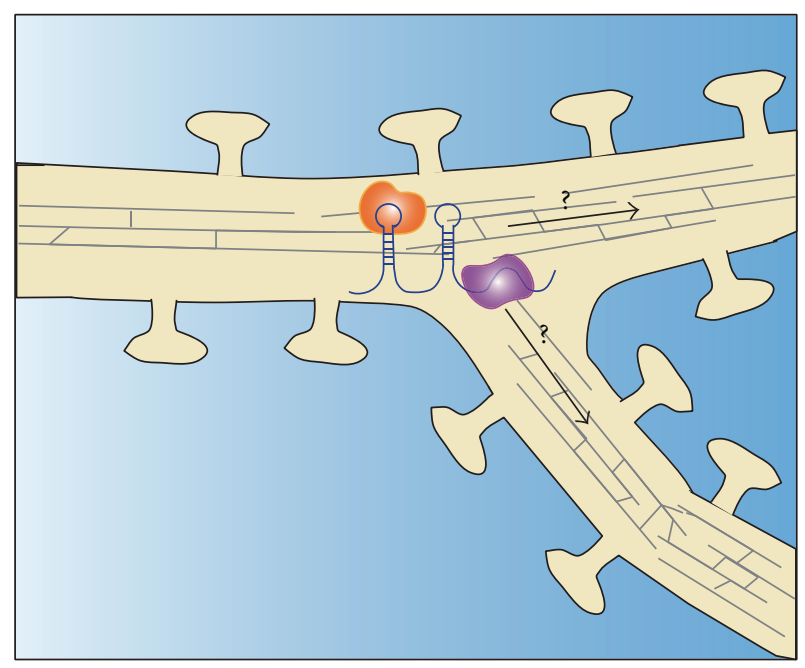

(b)

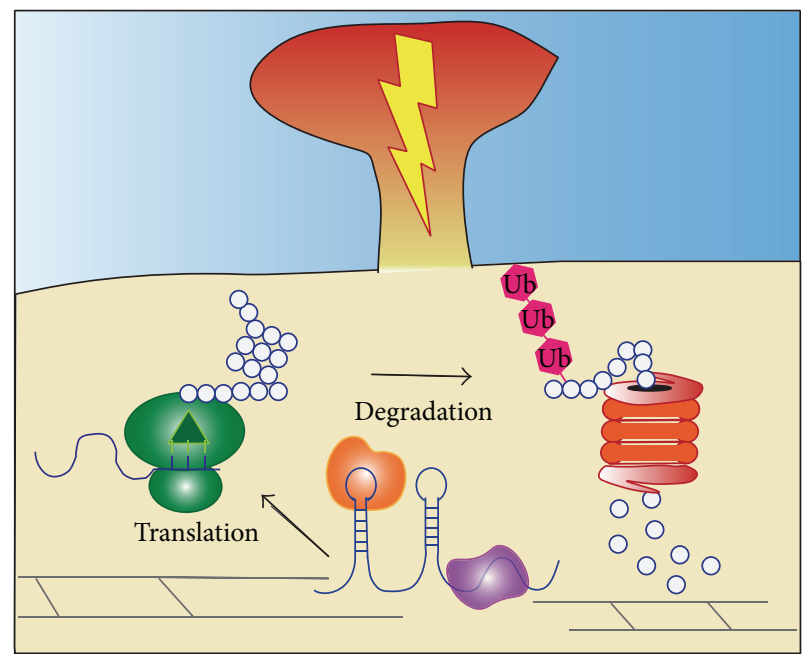

Amino acid

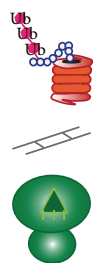

Ubiquitin proteasome

system (UPS)

Microtubules

Protein translation machinery

FIgURE 1: The trials and tribulations of RBPs and RNPs. (a) RBPs assemble cotranscriptionally and regulate mRNA splicing and modification preventing the coassembly of multiple mRNAs per RNP. Motifs in the $5^{\prime}$ UTR and $3^{\prime}$ UTR as well as retained intronic sequences facilitate dendritic targeting of RNPs. (b) RBPs transport mRNAs along microtubules to destinations dictated by the cargo mRNA sequence. Through input-specific events, synapses or dendritic branches may autonomously regulate their mRNA content. (c) Excitatory synapses at dendritic spines greatly outnumber mRNAs in dendrites and even more so counting inhibitory synapses. Despite being sparsely distributed, local mRNAs contribute significantly to synaptic function. (d) Upon synaptic stimulation, RBP function determines mRNA fate. Derepression by translational repressors can be followed by promotion of translation by RBPs like Sam68 (purple). Translation is counterbalanced by proteasomal or lysosomal degradation. 
neurons where synapses are thought to independently alter their morphology and function in response to neuronal activity via spatial restriction of gene expression. In addition to diffusion and transport of somatically generated proteins, synthesis from dendritically targeted mRNAs shapes the local proteome around synaptic contacts. The active transport of mRNAs into neuronal processes requires their association with RNA transport particles, which contain (1) specific RBPs to prevent translation prior to delivery, (2) adaptors for association with cytoskeletal translocation machinery, and (3) molecular motors [15] (Figure 1). A number of groups have identified dendritic targeting elements (DTEs) in the $3^{\prime}$ untranslated regions ( $3^{\prime}$ UTR) of mRNAs present in synaptodendritic compartments including CaMKII $\alpha$, beta actin, MAP2, ARC, and BDNF [16-24]. BDNF and CaMKII $\alpha$ isoforms with shortened $3^{\prime}$ UTRs lacking DTEs are not dendritically targeted, suggesting that alternative splicing of cis-elements can regulate mRNA localization $[16,25]$. One of the best-studied DTEs is the "zipcode" found in the $3^{\prime}$ UTR of beta-actin mRNA, which is recognized by the RBP Zipcode Binding Protein 1 (ZBP1) and is necessary for its transport and translational regulation [19]. Interestingly, the betaactin $3^{\prime}$ UTR contains an additional nonoverlapping DTE recognized by the RBP Src-Associated in Mitosis $68 \mathrm{KDa}$ (Sam68) [26]. We have shown that Sam68 is crucial for the dendritic transport and translation of beta-actin mRNA, similar to ZBP1 [27]. Whether multiple DTEs allow for concurrent binding of RBPs is an outstanding question in the field and will be addressed in more detail later in this review.

Diverse mRNA targeting mechanisms have been identified in neurons. Retained introns in cytoplasmic mRNAs represent an additional and surprising class of cis-acting dendritic targeting elements that are regulated by the spliceosome. Cytoplasmic intron-sequence retaining transcripts (CIRTs) contain intronic elements that are sufficient to target these mRNAs to dendrites [28-30]. The presence of spliceosome constituents in dendrites raises the intriguing possibility that localized splicing may represent a previously unappreciated activity-dependent cytoplasmic process [31]. In this manner, incompletely processed CIRTs could be transitionally repressed until fully spliced and made competent by the dendritic spliceosome [32]. Indeed, several RBPs implicated in splicing have been observed in synaptodendritic compartments [11,33] including Sam68 [34-38].

Many of the over 2550 mRNAs present in dendrites [39, 40] lack any known dendritic targeting element, suggesting the existence of an alternative targeting mechanism. Recent evidence implicates nonsequence specific, structural elements in both the $3^{\prime}$ UTRs and $5^{\prime}$ UTRs in mRNAs in dendritic and synaptic localization [23]. Structural G-quartet stem loops, rather than sequence recognition, have been implicated in how the RBP Fragile X Mental Retardation Protein (FMRP) binds to mRNA cargos [41-43]. However, recent additional evidence indicates binding sites may be present throughout the entire sequence [44] or at specific $3^{\prime}$ UTR sites [45]. Altogether, these findings suggest the existence of functionally distinct mechanisms to localize RNAs within neuronal processes and highlight the role of noncoding mRNA sequences in subcellular targeting. Recent genome-wide association studies suggest that mutations in noncoding targeting elements are linked with disease phenotypes, underscoring the importance of mRNA transport in supporting neuronal function $[46,47]$.

\section{RBPs and Input-Specific Translation}

Input specificity requires the localized expression of proteins following mRNA transport. Dendritic translation in neurons was first evidenced by the presence of ribosomes $[48,49]$ and mRNAs [50,51] closely associated with postsynaptic contacts. This was later confirmed by studies demonstrating that mechanically isolated dendrites are translation-competent $[24,52]$ and can sustain protein synthesis-dependent forms of synaptic plasticity $[24,53,54]$. Furthermore, the transport and localized translation of mRNAs are both synapse- and stimulus-specific [24].

RBPs like FMRP and ZBP1 mediate translational repression and release cargos locally in response to particular stimulus-driven posttranslational modifications. For example, locally active Src kinase phosphorylates ZBP1 upon arrival at the synapse, which reduces its affinity for betaactin mRNA and liberates it for subsequent translation [55]. Other RBPs are thought to directly promote protein synthesis. Sam68, for example, has been recently shown to positively regulate translation in neurons [34, 36, 37, 56-58]. Our group found that Sam68 regulates the levels of beta-actin mRNA and protein in synaptodendritic compartments [27]. We found that Sam68 regulates the loading of beta-actin mRNA onto polysomes isolated from synaptic fractions, suggesting that Sam68 promotes local protein synthesis. Sam68 was originally identified as Src binding partner [59] and phosphorylation of Sam 68 by both tyrosine and serinethreonine kinases has been shown to regulate its affinity for RNA [60-62]. Therefore, synaptic activity may trigger downstream signaling cascades that affect local Sam68-dependent protein synthesis. New research aimed at disentangling the molecular mechanisms that regulate the spatial and temporal derepression and translation of mRNAs will help to further our understanding of RBPs in synaptic function and brain disorders.

\section{Balancing Protein Synthesis and Degradation in Synaptic Plasticity and Disease}

Protein translation and degradation both contribute to proteostasis and are essential for proper synaptic function. Aberrant protein levels at synapses are thought to be pathogenic primarily by affecting the expression and/or maintenance of synaptic transmission and plasticity. Several ASD susceptibility genes encode for proteins that regulate translation, or proteasomal degradation (outlined below). These genes are also involved in the induction and expression of mGluRmediated long-term depression (mGluR-LTD), a type of synaptic plasticity that requires protein synthesis [63-65]. Deficits in mGluR-LTD have been observed in numerous 
mouse models of ASDs and other cognitive and neurodegenerative disorders such as Alzheimer's and Parkinson's disease [65-70]. One of the most widely studied examples is that of the translational repressor FMRP [44], whose absence leads to Fragile X Syndrome (FXS), the most common form of inherited intellectual disability in boys. FMRP binds to a plethora of mRNAs suggesting that the underlying pathology of FXS may result from broad translational dysregulation of the neuronal transcriptome [44]. Mice null for FMRP display general increases in basal protein synthesis [71] but lack translation in response to activation of mGluRs [72]. Paradoxically, FMRP KO mice exhibit exaggerated mGluRLTD despite a lack of mGluR-triggered protein synthesis. One theory is that elevated basal levels of plasticity-related proteins in the FMRP null mice bypass the need for mGluRtriggered translation, thus resulting in enhanced mGluRLTD, which may contribute to the neurological symptoms of FXS [73]. However, recent work from our group demonstrates that the magnitude of mGluR-LTD is not necessarily correlated with synaptic protein abundance [56]. Other deficits, including altered neuronal excitability [74-76] or decreased proteasome function $[77,78]$, could underlie the exaggerated LTD observed in FMRP null mice.

In addition to FXS and ASD, RBP dysfunction may also play a role in other disorders including schizophrenia and amyotrophic lateral sclerosis. The protein disrupted in schizophrenia-1 (DISC-1) [79] was recently identified as a novel RBP and a component of RNP granules [80]. Unregulated expression of DISC-1 has been associated with schizophrenia and clinical depression. DISC-1 appears to be important for dendritic mRNA transport and for maintenance of late phase long-term potentiation (L-LTP) [80]. Accumulation of the transactive response DNA-binding protein-43 (TDP-43) in the cytoplasm is evident in sporadic forms of amyotrophic lateral sclerosis, frontotemporal dementia, and Alzheimer's disease [81]. TDP-43 binds to DNA and RNA and has been shown to regulate splicing, mRNA stability, and mRNA transport and translation as well as synaptic function in motor neurons $[82,83]$. These results suggest a broad role for RBP in normal and pathological brain function.

Consistent with links between unbalanced protein levels and disease, several neuropsychiatric disorders have been associated with mutations in components of the ubiquitin proteasome system (UPS) [84-86] including Parkinson's disease, spinocerebellar ataxia, X-Linked Mental Retardation, and Angelman Syndrome [87-92]. Evidence for transport of proteasomal subunits and E3 ligases into dendritic spines [93] and activity-dependent ubiquitination of the synaptic proteome [94, 95] suggests that local effects of the UPS contribute to synaptic proteostasis and input specificity. Since the UPS degrades proteins, one might expect that pathologies associated with impaired UPS function would arise from a toxic accumulation of substrates. However, this is not always the case, suggesting that UPS function is more complex than initially imagined [96]. For example, monoubiquitination of diverse synaptic proteins can regulate synaptic transmission independent of protein degradation $[97,98]$. Nonproteolytic monoubiquitination of the RBP CPEB3 regulates dendritic spine growth and AMPA receptor abundance and ultimately regulates learning and memory [99]. Moreover, monoubiquitination of PSD95 $[100,101]$ and PICK1 by Parkin [102] may regulate the surface expression of AMPA subunits and the acid sensing channel, respectively. Several groups have demonstrated acute inhibition of the proteasome affects long-term plasticity, but there is some disagreement in the literature on the nature of the disruptions [56, 103-106].

In the case of FXS, studies demonstrate that FMRP is rapidly degraded by the proteasome during the induction of synaptic plasticity $[105,107]$. Therefore, mutations that inhibit proteasomal degradation of FMRP may lead to altered plasticity and result in neuropsychiatric symptoms. Consistent with this hypothesis, a recent study discovered that loss of the E3 ubiquitin ligase Cdhl-APC prevents FMRP degradation, as well as the induction of mGluR-LTD [108]. Furthermore, previous work in the Cdh1 knockout mouse identified a deficit in late phase LTP and contextual fear conditioning [109]. Therefore, the interaction between FMRP and Cdhl-APC may be essential for multiple forms of plasticity and memory formation. Presumably, degradation of FMRP would positively impact the translation of its cargo mRNAs to support long-term postsynaptic changes, though the direct effect of FMRP degradation on protein levels remains to be addressed.

Fragile X Tremor Ataxia Syndrome (FXTAS) is a neurodegenerative disorder characterized by adult-onset ataxia and cognitive decline. In FXTAS, a pathogenic premutation trinucleotide repeat expansion (50-200 repeats) in the $5^{\prime}$ UTR of the FMR1 gene (FMRP) does not result in transcriptional repression but rather causes a toxic gain-of-function through the formation of intranuclear inclusions containing the FMR1 mRNA and sequestered RBPs [110]. Recent work suggests that the sequestration of crucial cellular factors, including Sam68, into these intranuclear inclusions contributes to the cognitive deficits observed in FXTAS [111]. Indeed, Sam68 is functionally impaired in FXTAS patient tissue [111] and accumulation at intranuclear inclusions precedes other deficits, suggesting that loss of Sam68 function plays a causal role in FXTAS [111]. Sam68 KO mice display ataxia $[57,112]$ and both Sam68 KO mice and primary neurons lacking Sam68 display deficits in dendritic spine morphology [27], which is also seen in other FXTAS models using expanded CGG repeats [113].

We have recently shown that Sam68 is critically involved in coordinating mRNA translation and degradation via the proteasome during the induction of synaptic plasticity. Sam68 is likely necessary to promote the rapid translation of several plasticity-related proteins in response to mGluR activation. In Sam68 KO animals, the balance of proteostasis is abnormal and tipped towards degradation. Interestingly, Sam68 KO mice display impaired mGluR-LTD that can be rescued by blocking the proteasome [56]. In our model, rapid proteasomal degradation acts as a homeostatic scaling mechanism to prevent the accumulation of plasticity-related proteins and thus the induction of further rounds of mGluRLTD, independent of mGluR activation. Our recent research has put together a more nuanced view of synaptic proteostasis in synaptic plasticity, as a push-pull between RBP-mediated translation and proteasomal degradation. Disruptions to this 
balance may underlie the pathogenesis of neuropsychiatric disorders including FXTAS.

\section{Unanswered Questions}

5.1. Is There Presynaptic Protein Synthesis? In accordance with current scientific research, the bulk of this review has focused on the mechanisms by which RBPs regulate postsynaptic sites. However, many forms of synaptic plasticity are presynaptically expressed in vertebrate and invertebrate preparations and may require protein synthesis [114-116]. Over $300 \mathrm{mRNA}$ species identified in mature axons include transcripts encoding for components of the translation machinery [117]. During development, the RBPs ZBP1, FMRP, and CPEB respond to stimulus-specific cues in axonal growth cones to mediate mRNA translation [41, 118-121] and ZBP1 localizes at axonal branch points where it mediates beta-actin mRNA translation and branch stabilization [122]. In mature axons, it was recently shown that amyloid beta peptides stimulate the axonal synthesis of the transcription factor ATF4 among other proteins, which can shuttle into the presynaptic nucleus and initiate cell death [123]. It has been postulated that axons use a different type of translation machinery (e.g. monosomes v. polysomes) $[124,125]$ and that ribosomes are localized to electron-dense regions and/or tethered to the cell membrane within the axon $[125,126]$. This may explain why structural evidence for presynaptic/axonal ribosomes is scarce. As many neuronal subtypes have highly branched axonal projections that synapse on multiple neurons, one would also expect input-specific regulation of presynaptic function. RBPs provide a plausible mechanism by which this regulation could be accomplished in adult CNS axons. The development and implementation of new strategies to isolate and visualize axons and presynaptic compartments should inform this line of study.

5.2. How Is Specificity Achieved Given the Ratio of Synapses to RNAs? The breadth of the dendritic transcriptome supports an important role for local translation in long-term plasticity [39]. However, the mRNAs for many important synaptic proteins such as BDNF, GluA2, SHANK, and ARC are conspicuous in their scarcity or absence in the dendrite $[6,9$, $13,23]$. Furthermore, the number of even the most abundant dendritic mRNAs (beta-actin and CaMKII $\alpha$ ) is typically an order of magnitude less than the number of synapses. This discrepancy poses the simple mechanistic problem that there are not nearly enough mRNAs to supply proteins on a one to one basis with synapses as required. This problem may be circumvented by a high translational efficiency of synaptic mRNAs, with each mRNA being translated many times to produce an adequate number of proteins. Newly synthesized proteins would then traffic towards the appropriate synapse and thus few mRNAs could supply proteins to an entire dendritic branch, rather than a single dendritic spine or synapse. To our knowledge, direct measurements of mRNA translational efficiency at synapses have been prohibitively difficult to obtain. Exciting new developments in fluorescent tagging, including spaghetti monster fluorescent proteins [127] and SunTag [128], may soon allow for the direct visualization and measurement of local translation.

Additionally, electron microscopy studies in adult hippocampus reveal that there are far fewer dendritic polysomes (the presumed sites of local translation) than synapses [129131]. Perhaps only a subset of synapses undergo long-term morphological and functional changes or require protein synthesis to do so. Large dendritic spines containing the spine apparatus and endoplasmic reticulum [132] could comprise this group. Alternatively, the rapid and bidirectional transport of mRNAs by RBPs towards active synapses along neuronal dendrites may be an ongoing process long after transcription [133]. In this case, synapses undergoing plasticity might physically capture transporting mRNP granules through unknown mechanisms. Indeed, a portion of dendritic beta-actin mRNAs display active and bidirectional transport [134] and polysomes themselves can redistribute from dendritic shafts into spines in response to a plasticityinducing stimulus [135].

As we propose in the previous paragraphs, the discovery of motile dendritic RNPs suggests that the local area served by a single mRNA may well be a dendritic branch rather than a single spine. Recent work suggests CaMKII $\alpha$ mRNA and protein demonstrate branch specificity in response to mTOR activity [136]. If the dendritic branch rather than individual synapses represents the consolidated integrative unit underlying translation-dependent forms of plasticity as previously suggested $[137,138]$, then input specificity might refer to a branch, rather than an individual synaptic junction. Under these conditions, having few dynamically transported mRNAs at each dendritic branch may be sufficient for plasticity. New massively multiplexed, FISH-based techniques to localize all the mRNAs in a neuron will allow for the determination of the spatial relationship of mRNAs to synapses and branch points $[139,140]$. In concert with these new techniques, further experiments using more physiological inductions of plasticity along with mRNA visualization will be of great benefit in elucidating the movements of dendritic mRNAs and the spatial extent of "local" translation.

5.3. What Is the Contribution of Locally Translated Protein to the Existing Local Pool? To our knowledge, accurate numbers of actin molecules at neuronal dendritic spines have not been calculated and likely vary substantially based on conditions. However, an estimate based on studies of stereocilia of the inner ear [141], which are actin-rich protrusions of similar size, suggests $10^{5}$ actin molecules per spine (each stereocilia contains $\sim 100-700$ actin filaments on average and 370 actin molecules per micron of actin filament). Considering ribosomal processing speeds (6-9 amino acids/sec) [142] and the size of beta actin, we estimate that one beta-actin protein can be produced every 50 seconds, or 36 beta-actin molecules can be produced in 30 minutes per mRNA and per ribosome. Even considering multiple mRNAs and polyribosomes, the amount of newly synthesized beta-actin would likely represent only a small fraction of available synaptic molecules. If the transport and translation of beta-actin mRNAs into dendritic spines contribute to morphological 
plasticity following synaptic stimulation, then a rationale must be found for why this population must be newly made as opposed to being recycled from large synaptic pools or transported from the cell body. Temporally regulated irreversible posttranslational modifications may functionally distinguish beta-actin molecules. Indeed, newly synthesized beta-actin localizes at the leading edge of filament formation, perhaps through fast arginylation at the N-terminus [143], which has been previously shown to increase actin polymerization $[144,145]$. In addition, spatially regulated posttranslational modifications may also confer functional distinctions on newly synthesized proteins. BDNF synthesized at dendrites has been implicated in spine head growth and pruning, whereas BDNF synthesized in the cell body promotes spine formation [146]. Thus, though the contribution of local translation to total dendritic protein for highly abundant proteins may be small, the functional distinction of newly and locally synthesized proteins may be the primary effector of synaptic alterations. The recent development of techniques that enable the visualization and quantification of newly synthesized proteins, such as fluorescent noncanonical amino acid tagging (FUNCAT) [147], may provide new insight into the contribution of RBP-mediated local translation to the total protein pool.

\subsection{Do Multiple RBPs Bind to RNAs? Several mRNAs contain} nonoverlapping binding sites for diverse RBPs, suggesting complex and multifactorial regulation of mRNA metabolism. Beta-actin mRNA itself contains nonoverlapping binding sites for ZBP1 [19], Sam68 [26], and FMRP [45], although how these RBPs combine to regulate beta-actin metabolism is unknown. We compared Sam68 mRNA cargos identified using UV-crosslinking techniques [36] and found that 83.7\% of these mRNAs also bound to FMRP [44, 45]. As loss of protein synthesis promoted by Sam68 leads to impaired mGluR-LTD and loss of FMRP repression leads to enhanced mGluR-LTD [148], Sam68 and FMRP could bind cooperatively to bidirectionally regulate RNA cargo metabolism. Thus, Sam68 and FMRP may differentially regulate a common pool of dendritically expressed neuronal mRNAs to regulate synaptic function, although whether they bind at the same time is unclear. It is interesting to speculate how the opposing actions of these RBPs coordinate the metabolism of single mRNA. Perhaps diverse RBPs regulate stimulusspecific synaptic activity. In this way, a different translational response could be activated after a weak or strong stimulus, or from different types of synaptic activity (i.e., excitatory versus inhibitory, metabotropic versus ionotropic). Perhaps multi-RBP regulation of mRNAs provides additional layers of regulation for fine-tuning spatial and temporal protein expression. Answers to these questions remain unclear and will require additional experimentation.

\section{Conclusion}

To achieve proteostasis, neurons must spatially coordinate multiple cellular processes across thousands of synapses. In the cellular milieu, mRNAs are always packaged into ribonucleoprotein (RNP) granules, which coordinate the transport and translation of their cargo mRNAs. Disease causing mutations in mRNAs or RBPs may lead to disruption of mRNA packaging into granules and alter subsequent transport and translation. These pathological mechanisms underscore the importance of mRNA being in the right place at the right time, as well as the importance of mRNA as a structural platform to coordinate interactions between RBPs and associated proteins. However, many unanswered questions remain, including a lack of sufficient mRNA particles for synapses, the contribution of local translation to existing pools of protein, and the interactions and complex regulation of multiple RBPs per single mRNA. There are numerous limitations in studying mRNA trafficking and translation in neurons, such as the lack of an assay to determine the exact localization and timing of synthesized proteins (however, see [149]). Moreover, most transcriptional and mRNA transport processes have been studied in the context of strong and nonphysiological stimuli, such as bath application of neurotransmitters in cellular cultures. As techniques for single synapse stimulation and single molecule imaging of mRNA in live tissue improve, we may observe different behavior of mRNA transport under more physiological stimulation paradigms.

\section{Conflict of Interests}

The authors declare that there is no conflict of interests regarding the publication of this paper.

\section{References}

[1] A. R. Buxbaum, G. Haimovich, and R. H. Singer, "In the right place at the right time: visualizing and understanding mRNA localization," Nature Reviews Molecular Cell Biology, vol. 16, no. 2, pp. 95-109, 2015.

[2] G. Elvira, S. Wasiak, V. Blandford et al., "Characterization of an RNA granule from developing brain," Molecular and Cellular Proteomics, vol. 5, no. 4, pp. 635-651, 2006.

[3] R. Fritzsche, D. Karra, K. L. Bennett et al., "Interactome of two diverse RNA granules links mRNA localization to translational repression in neurons," Cell Reports, vol. 5, no. 6, pp. 1749-1762, 2013.

[4] Y. Kanai, N. Dohmae, and N. Hirokawa, "Kinesin transports RNA: isolation and characterization of an RNA-transporting granule," Neuron, vol. 43, no. 4, pp. 513-525, 2004.

[5] B. M. Lunde, C. Moore, and G. Varani, "RNA-binding proteins: modular design for efficient function," Nature Reviews Molecular Cell Biology, vol. 8, no. 6, pp. 479-490, 2007.

[6] M. Batish, P. van den Bogaard, F. R. Kramer, and S. Tyagi, "Neuronal mRNAs travel singly into dendrites," Proceedings of the National Academy of Sciences of the United States of America, vol. 109, no. 12, pp. 4645-4650, 2012.

[7] A. R. Buxbaum, B. Wu, and R. H. Singer, "Single beta-actin mRNA detection in neurons reveals a mechanism for regulating its translatability," Science, vol. 343, no. 6169, pp. 419-422, 2014.

[8] S. Farris, G. Lewandowski, C. D. Cox, and O. Steward, "Selective localization of Arc mRNA in dendrites involves activity- and translation-dependent mRNA degradation," The Journal of Neuroscience, vol. 34, no. 13, pp. 4481-4493, 2014. 
[9] V. M. Ho, L. O. Dallalzadeh, N. Karathanasis et al., "GluA2 mRNA distribution and regulation by miR-124 in hippocampal neurons," Molecular and Cellular Neuroscience, vol. 61, pp. 1-12, 2014.

[10] B. A. Jordan, B. D. Fernholz, M. Boussac et al., "Identification and verification of novel rodent postsynaptic density proteins," Molecular and Cellular Proteomics, vol. 3, no. 9, pp. 857-871, 2004.

[11] G. Zhang, T. A. Neubert, and B. A. Jordan, "RNA binding proteins accumulate at the postsynaptic density with synaptic activity," The Journal of Neuroscience, vol. 32, no. 2, pp. 599-609, 2012.

[12] M. Kato, T. W. Han, S. Xie et al., "Cell-free formation of RNA granules: low complexity sequence domains form dynamic fibers within hydrogels," Cell, vol. 149, no. 4, pp. 753-767, 2012.

[13] A. M. Krichevsky and K. S. Kosik, "Neuronal RNA granules: a link between RNA localization and stimulation-dependent translation," Neuron, vol. 32, no. 4, pp. 683-696, 2001.

[14] D. St. Johnston, "Moving messages: the intracellular localization of mRNAs," Nature Reviews Molecular Cell Biology, vol. 6, no. 5, pp. 363-375, 2005.

[15] W. S. Sossin and L. DesGroseillers, "Intracellular trafficking of RNA in neurons," Traffic, vol. 7, no. 12, pp. 1581-1589, 2006.

[16] J. J. An, K. Gharami, G.-Y. Liao et al., "Distinct role of long 3' UTR BDNF mRNA in spine morphology and synaptic plasticity in hippocampal neurons," Cell, vol. 134, no. 1, pp. 175-187, 2008.

[17] A. Blichenberg, B. Schwanke, M. Rehbein, C. C. Garner, D. Richter, and S. Kindler, "Identification of a cis-acting dendritic targeting element in MAP2 mRNAs," The Journal of Neuroscience, vol. 19, no. 20, pp. 8818-8829, 1999.

[18] T. M. Böckers, M. Segger-Junius, P. Iglauer et al., "Differential expression and dendritic transcript localization of Shank family members: identification of a dendritic targeting element in the $3^{\prime}$ untranslated region of Shank1 mRNA," Molecular and Cellular Neuroscience, vol. 26, no. 1, pp. 182-190, 2004.

[19] T. Eom, L. N. Antar, R. H. Singer, and G. J. Bassell, "Localization of a beta-actin messenger ribonucleoprotein complex with zipcode-binding protein modulates the density of dendritic filopodia and filopodial synapses," The Journal of Neuroscience, vol. 23, no. 32, pp. 10433-10444, 2003.

[20] I. Epstein, G. Tushev, T. J. Will, I. Vlatkovic, I. J. Cajigas, and E. M. Schuman, "Alternative polyadenylation and differential expression of Shank mRNAs in the synaptic neuropil," Philosophical Transactions of the Royal Society B: Biological Sciences, vol. 369, no. 1633, 2014.

[21] H. Kobayashi, S. Yamamoto, T. Maruo, and F. Murakami, "Identification of a cis-acting element required for dendritic targeting of activity-regulated cytoskeleton-associated protein mRNA," European Journal of Neuroscience, vol. 22, no. 12, pp. 2977-2984, 2005.

[22] M. Mayford, D. Baranes, K. Podsypanina, and E. R. Kandel, "The $3^{\prime}$-untranslated region of CaMKII $\alpha$ is a cis-acting signal for the localization and translation of mRNA in dendrites," Proceedings of the National Academy of Sciences of the United States of America, vol. 93, no. 23, pp. 13250-13255, 1996.

[23] E. J. Meer, D. O. Wang, S. Kim, I. Barr, F. Guo, and K. C. Martin, "Identification of a cis-acting element that localizes mRNA to synapses," Proceedings of the National Academy of Sciences of the United States of America, vol. 109, no. 12, pp. 4639-4644, 2012.

[24] D. O. Wang, S. M. Kim, Y. Zhao et al., "Synapse- and stimulusspecific local translation during long-term neuronal plasticity," Science, vol. 324, no. 5934, pp. 1536-1540, 2009.
[25] A. Blichenberg, M. Rehbein, R. Muller, C. C. Garner, D. Richter, and S. Kindler, "Identification of a cis-acting dendritic targeting element in the mRNA encoding the alpha subunit of $\mathrm{Ca}^{2+} /$ calmodulin-dependent protein kinase II," The European Journal of Neuroscience, vol. 13, no. 10, pp. 1881-1888, 2001.

[26] M. Itoh, I. Haga, Q.-H. Li, and J.-I. Fujisawa, "Identification of cellular mRNA targets for RNA-binding protein Sam68," Nucleic Acids Research, vol. 30, no. 24, pp. 5452-5464, 2002.

[27] M. E. Klein, T. J. Younts, P. E. Castillo, and B. A. Jordan, "RNA-binding protein Sam68 controls synapse number and local $\beta$-actin mRNA metabolism in dendrites," Proceedings of the National Academy of Sciences of the United States of America, vol. 110, no. 8, pp. 3125-3130, 2013.

[28] T. J. Bell, K. Y. Miyashiro, J.-Y. Sul et al., "Cytoplasmic BK(Ca) channel intron-containing mRNAs contribute to the intrinsic excitability of hippocampal neurons," Proceedings of the National Academy of Sciences of the United States of America, vol. 105, no. 6, pp. 1901-1906, 2008.

[29] P. T. Buckley, M. T. Lee, J.-Y. Sul et al., "Cytoplasmic intron sequence-retaining transcripts can be dendritically targeted via ID element retrotransposons," Neuron, vol. 69, no. 5, pp. 877884,2011

[30] M. Khaladkar, P. T. Buckley, M. T. Lee et al., "Subcellular RNA sequencing reveals broad presence of cytoplasmic intronsequence retaining transcripts in mouse and rat neurons," PLoS ONE, vol. 8, no. 10, Article ID e76194, 2013.

[31] J. Glanzer, K. Y. Miyashiro, J.-Y. Sul et al., "RNA splicing capability of live neuronal dendrites," Proceedings of the National Academy of Sciences of the United States of America, vol. 102, no. 46, pp. 16859-16864, 2005.

[32] P. T. Buckley, M. Khaladkar, J. Kim, and J. Eberwine, "Cytoplasmic intron retention, function, splicing, and the sentinel RNA hypothesis," Wiley Interdisciplinary Reviews: RNA, vol. 5, no. 2, pp. 223-230, 2014.

[33] B. A. Jordan and E. Ziff, Eds., To the Nucleus with Proteomics, Springer, 2007.

[34] N. Ben Fredj, J. Grange, R. Sadoul, S. Richard, Y. Goldberg, and V. Boyer, "Depolarization-induced translocation of the RNA-binding protein Sam68 to the dendrites of hippocampal neurons," Journal of Cell Science, vol. 117, no. 7, pp. 1079-1090, 2004.

[35] G. Chawla, C.-H. Lin, A. Han, L. Shiue, M. Ares Jr., and D. L. Black, "Sam68 regulates a set of alternatively spliced exons during neurogenesis," Molecular and Cellular Biology, vol. 29, no. 1, pp. 201-213, 2009.

[36] J. Grange, A. Belly, S. Dupas, A. Trembleau, R. Sadoul, and Y. Goldberg, "Specific interaction between Sam68 and neuronal mRNAs: implication for the activity-dependent biosynthesis of elongation factor eEF1A," Journal of Neuroscience Research, vol. 87, no. 1, pp. 12-25, 2009.

[37] J. Grange, V. Boyer, R. Fabian-Fine, N. B. Fredj, R. Sadoul, and Y. Goldberg, "Somatodendritic localization and mRNA association of the splicing regulatory protein Sam68 in the hippocampus and cortex," Journal of Neuroscience Research, vol. 75, no. 5, pp. 654-666, 2004.

[38] T. Iijima, Y. Iijima, H. Witte, and P. Scheiffele, "Neuronal cell type-specific alternative splicing is regulated by the $\mathrm{KH}$ domain protein SLM1," The Journal of Cell Biology, vol. 204, no. 3, pp. 331-342, 2014.

[39] I. J. Cajigas, G. Tushev, T. J. Will, S. Tom Dieck, N. Fuerst, and E. M. Schuman, "The local transcriptome in the synaptic neuropil 
revealed by deep sequencing and high-resolution imaging," Neuron, vol. 74, no. 3, pp. 453-466, 2012.

[40] J. Eberwine, K. Miyashiro, J. Estee Kacharmina, and C. Job, "Local translation of classes of mRNAs that are targeted to neuronal dendrites," Proceedings of the National Academy of Sciences of the United States of America, vol. 98, no. 13, pp. 70807085, 2001.

[41] J. C. Darnell, K. B. Jensen, P. Jin, V. Brown, S. T. Warren, and R. B. Darnell, "Fragile X mental retardation protein targets $\mathrm{G}$ quartet mRNAs important for neuronal function," Cell, vol. 107, no. 4, pp. 489-499, 2001.

[42] H. Siomi, M. C. Siomi, R. L. Nussbaum, and G. Dreyfuss, “The protein product of the fragile $\mathrm{X}$ gene, FMR1, has characteristics of an RNA-binding protein," Cell, vol. 74, no. 2, pp. 291-298, 1993.

[43] C. Verhelj, C. E. Bakker, E. de Graaff et al., "Characterization and localization of the FMR-1 gene product associated with fragile X syndrome," Nature, vol. 363, no. 6431, pp. 722-724, 1993.

[44] J. C. Darnell, S. J. Van Driesche, C. Zhang et al., "FMRP stalls ribosomal translocation on mRNAs linked to synaptic function and autism," Cell, vol. 146, no. 2, pp. 247-261, 2011.

[45] M. Ascano Jr., N. Mukherjee, P. Bandaru et al., "FMRP targets distinct mRNA sequence elements to regulate protein expression," Nature, vol. 492, no. 7429, pp. 382-386, 2012.

[46] M. Arnold, D. C. Ellwanger, M. L. Hartsperger, A. Pfeufer, and V. Stümpflen, "Cis-acting polymorphisms affect complex traits through modifications of MicroRNA regulation pathways," PLoS ONE, vol. 7, no. 5, Article ID e36694, 2012.

[47] M. Halvorsen, J. S. Martin, S. Broadaway, and A. Laederach, "Disease-associated mutations that alter the RNA structural ensemble," PLoS Genetics, vol. 6, no. 8, Article ID 1001074, 2010.

[48] O. Steward and W. B. Levy, "Preferential localization of polyribosomes under the base of dendritic spines in granule cells of the dentate gyrus," The Journal of Neuroscience, vol. 2, no. 3, pp. 284-291, 1982.

[49] M. A. Sutton and E. M. Schuman, "Dendritic protein synthesis, synaptic plasticity, and memory," Cell, vol. 127, no. 1, pp. 49-58, 2006.

[50] K. C. Martin and R. S. Zukin, "RNA trafficking and local protein synthesis in dendrites: an overview," The Journal of Neuroscience, vol. 26, no. 27, pp. 7131-7134, 2006.

[51] E. M. Schuman, J. L. Dynes, and O. Steward, "Synaptic regulation of translation of dendritic mRNAs," The Journal of Neuroscience, vol. 26, no. 27, pp. 7143-7146, 2006.

[52] G. Aakalu, W. B. Smith, N. Nguyen, C. Jiang, and E. M. Schuman, "Dynamic visualization of local protein synthesis in hippocampal neurons," Neuron, vol. 30, no. 2, pp. 489-502, 2001.

[53] H. Kang and E. M. Schuman, "A requirement for local protein synthesis in neurotrophin-induced hippocampal synaptic plasticity," Science, vol. 273, no. 5280, pp. 1402-1406, 1996.

[54] K. G. Reymann and J. U. Frey, "The late maintenance of hippocampal LTP: requirements, phases, 'synaptic tagging', 'late-associativity' and implications,' Neuropharmacology, vol. 52, no. 1, pp. 24-40, 2007.

[55] S. Hüttelmaier, D. Zenklusen, M. Lederer et al., "Spatial regulation of $\beta$-actin translation by Src-dependent phosphorylation of ZBP1," Nature, vol. 438, no. 7067, pp. 512-515, 2005.

[56] M. E. Klein, P. E. Castillo, and B. A. Jordan, "Coordination between translation and degradation regulates inducibility of mGluR-LTD," Cell Reports, vol. 10, no. 9, pp. 1459-1466, 2015.
[57] K. E. Lukong and S. Richard, "Motor coordination defects in mice deficient for the Sam68 RNA-binding protein," Behavioural Brain Research, vol. 189, no. 2, pp. 357-363, 2008.

[58] M. P. Paronetto, V. Messina, E. Bianchi et al., "Sam68 regulates translation of target mRNAs in male germ cells, necessary for mouse spermatogenesis," The Journal of Cell Biology, vol. 185, no. 2, pp. 235-249, 2009.

[59] S. J. Taylor and D. Shalloway, "An RNA-binding protein associated with Src through its SH2 and SH3 domains in mitosis," Nature, vol. 368, no. 6474, pp. 867-871, 1994.

[60] T. Chen, B. B. Damaj, C. Herrera, P. Lasko, and S. Richard, "Selfassociation of the single-KH-domain family members Sam68, GRP33, GLD-1, and Qk1: role of the KH domain," Molecular and Cellular Biology, vol. 17, no. 10, pp. 5707-5718, 1997.

[61] J. J. Derry, S. Richard, H. V. Carvajal et al., "Sik (BRK) phosphorylates sam68 in the nucleus and negatively regulates its RNA binding ability," Molecular and Cellular Biology, vol. 20, no. 16, pp. 6114-6126, 2000.

[62] Q. Lin, S. J. Taylor, and D. Shalloway, "Specificity and determinants of Sam68 RNA binding. Implications for the biological function of K homology domains," The Journal of Biological Chemistry, vol. 272, no. 43, pp. 27274-27280, 1997.

[63] M. Costa-Mattioli, W. S. Sossin, E. Klann, and N. Sonenberg, "Translational control of long-lasting synaptic plasticity and memory," Neuron, vol. 61, no. 1, pp. 10-26, 2009.

[64] K. M. Huber, M. S. Kayser, and M. F. Bear, "Role for rapid dendritic protein synthesis in hippocampal mGluR-dependent long-term depression," Science, vol. 288, no. 5469, pp. 1254-1257, 2000.

[65] C. Lüscher and K. M. Huber, "Group 1 mGluR-dependent synaptic long-term depression: mechanisms and implications for circuitry and disease," Neuron, vol. 65, no. 4, pp. 445-459, 2010.

[66] B. D. Auerbach, E. K. Osterweil, and M. F. Bear, "Mutations causing syndromic autism define an axis of synaptic pathophysiology," Nature, vol. 480, no. 7375, pp. 63-68, 2011.

[67] S. A. Buffington, W. Huang, and M. Costa-Mattioli, "Translational control in synaptic plasticity and cognitive dysfunction," Annual Review of Neuroscience, vol. 37, pp. 17-38, 2014.

[68] C. G. Gkogkas, A. Khoutorsky, I. Ran et al., "Autism-related deficits via dysregulated eIF4E-dependent translational control," Nature, vol. 493, no. 7432, pp. 371-377, 2013.

[69] E. Santini, T. N. Huynh, A. F. MacAskill et al., "Exaggerated translation causes synaptic and behavioural aberrations associated with autism," Nature, vol. 493, no. 7432, pp. 411-415, 2013.

[70] H. Y. Zoghbi and M. F. Bear, "Synaptic dysfunction in neurodevelopmental disorders associated with autism and intellectual disabilities," Cold Spring Harbor Perspectives in Biology, vol. 4, 2012.

[71] M. Qin, J. Kang, T. V. Burlin, C. Jiang, and C. B. Smith, "Postadolescent changes in regional cerebral protein synthesis: an in vivo study in the Fmrl null mouse," The Journal of Neuroscience, vol. 25, no. 20, pp. 5087-5095, 2005.

[72] J. C. Darnell and E. Klann, "The translation of translational control by FMRP: therapeutic targets for FXS," Nature Neuroscience, vol. 16, no. 11, pp. 1530-1536, 2013.

[73] M. F. Bear, K. M. Huber, and S. T. Warren, “The mGluR theory of fragile X mental retardation," Trends in Neurosciences, vol. 27, no. 7, pp. 370-377, 2004. 
[74] P.-Y. Deng, Z. Rotman, J. A. Blundon et al., "FMRP regulates neurotransmitter release and synaptic information transmission by modulating action potential duration via BK channels," Neuron, vol. 77, no. 4, pp. 696-711, 2013.

[75] L. Ferron, M. Nieto-Rostro, J. S. Cassidy, and A. C. Dolphin, "Fragile X mental retardation protein controls synaptic vesicle exocytosis by modulating N-type calcium channel density," Nature Communications, vol. 5, article 3628, 2014.

[76] Y. Zhang, M. R. Brown, C. Hyland et al., "Regulation of neuronal excitability by interaction of fragile $\mathrm{X}$ mental retardation protein with slack potassium channels," The Journal of Neuroscience, vol. 32, no. 44, pp. 15318-15327, 2012.

[77] N.-P. Tsai, J. R. Wilkerson, W. Guo et al., "Multiple autismlinked genes mediate synapse elimination via proteasomal degradation of a synaptic scaffold PSD-95," Cell, vol. 151, no. 7, pp. 1581-1594, 2012.

[78] W. Zhao, S.-C. Chuang, S. R. Young, R. Bianchi, and R. K. S. Wong, "Extracellular glutamate exposure facilitates group I mGluR-mediated epileptogenesis in the hippocampus," The Journal of Neuroscience, vol. 35, no. 1, pp. 308-315, 2015.

[79] A. de Bartolomeis, G. Latte, C. Tomasetti, and F. Iasevoli, "Glutamatergic postsynaptic density protein dysfunctions in synaptic plasticity and dendritic spines morphology: relevance to schizophrenia and other behavioral disorders pathophysiology, and implications for novel therapeutic approaches," Molecular Neurobiology, vol. 49, no. 1, pp. 484-511, 2014.

[80] D. Tsuboi, K. Kuroda, M. Tanaka et al., "Disrupted-inschizophrenia 1 regulates transport of ITPR1 mRNA for synaptic plasticity," Nature Neuroscience, vol. 18, no. 5, pp. 698-707, 2015.

[81] A. S. L. Ng, R. Rademakers, and B. L. Miller, "Frontotemporal dementia: a bridge between dementia and neuromuscular disease," Annals of the New York Academy of Sciences, vol. 1338, pp. 71-93, 2015.

[82] R. Gulino, S. Forte, R. Parenti, and M. Gulisano, “TDP-43 as a modulator of synaptic plasticity in a mouse model of spinal motoneuron degeneration," CNS \& Neurological DisordersDrug Targets, vol. 14, no. 1, pp. 55-60, 2015.

[83] R. Gulino, R. Parenti, and M. Gulisano, "Novel mechanisms of spinal cord plasticity in a mouse model of motoneuron disease," BioMed Research International, vol. 2015, Article ID 654637, 10 pages, 2015.

[84] B. Bingol and M. Sheng, "Deconstruction for reconstruction: the role of proteolysis in neural plasticity and disease," Neuron, vol. 69, no. 1, pp. 22-32, 2011.

[85] N. P. Dantuma and L. C. Bott, "The ubiquitin-proteasome system in neurodegenerative diseases: precipitating factor, yet part of the solution," Frontiers in Molecular Neuroscience, vol. 7, article 70, 2014.

[86] H.-C. Tai and E. M. Schuman, "Ubiquitin, the proteasome and protein degradation in neuronal function and dysfunction," Nature Reviews Neuroscience, vol. 9, no. 11, pp. 826-838, 2008.

[87] A. C. Belin and M. Westerlund, "Parkinson's disease: a genetic perspective," FEBS Journal, vol. 275, no. 7, pp. 1377-1383, 2008.

[88] A. M. Dueñas, R. Goold, and P. Giunti, "Molecular pathogenesis of spinocerebellar ataxias," Brain, vol. 129, no. 6, pp. 1357-1370, 2006.

[89] M. Field, P. S. Tarpey, R. Smith et al., "Mutations in the BRWD3 gene cause X-linked mental retardation associated with macrocephaly," The American Journal of Human Genetics, vol. 81, no. 2, pp. 367-374, 2007.
[90] G. Froyen, M. Corbett, J. Vandewalle et al., "Submicroscopic duplications of the hydroxysteroid dehydrogenase HSD17B10 and the E3 ubiquitin ligase HUWE1 are associated with mental retardation," The American Journal of Human Genetics, vol. 82, no. 2, pp. 432-443, 2008.

[91] M. Lalande and M. A. Calciano, "Molecular epigenetics of Angelman syndrome," Cellular and Molecular Life Sciences, vol. 64, no. 7-8, pp. 947-960, 2007.

[92] P. S. Tarpey, F. L. Raymond, S. O’Meara et al., "Mutations in $C U L 4 B$, which encodes a ubiquitin E3 ligase subunit, cause an $\mathrm{X}$-linked mental retardation syndrome associated with aggressive outbursts, seizures, relative macrocephaly, central obesity, hypogonadism, pes cavus, and tremor," American Journal of Human Genetics, vol. 80, no. 2, pp. 345-352, 2007.

[93] B. Bingol and E. M. Schuman, "Activity-dependent dynamics and sequestration of proteasomes in dendritic spines," Nature, vol. 441, no. 7097, pp. 1144-1148, 2006.

[94] M. D. Ehlers, "Activity level controls postsynaptic composition and signaling via the ubiquitin-proteasome system," Nature Neuroscience, vol. 6, no. 3, pp. 231-242, 2003.

[95] J. J. Yi and M. D. Ehlers, "Ubiquitin and protein turnover in synapse function," Neuron, vol. 47, no. 5, pp. 629-632, 2005.

[96] D. J. Moore, "Parkin: a multifaceted ubiquitin ligase," Biochemical Society Transactions, vol. 34, no. 5, pp. 749-753, 2006.

[97] A. W. Lin and H.-Y. Man, "Ubiquitination of neurotransmitter receptors and postsynaptic scaffolding proteins," Neural Plasticity, vol. 2013, Article ID 432057, 10 pages, 2013.

[98] L. A. Schwarz and G. N. Patrick, "Ubiquitin-dependent endocytosis, trafficking and turnover of neuronal membrane proteins," Molecular and Cellular Neuroscience, vol. 49, no. 3, pp. 387-393, 2012.

[99] E. Pavlopoulos, P. Trifilieff, V. Chevaleyre et al., "Neuralized1 activates CPEB3: a function for nonproteolytic ubiquitin in synaptic plasticity and memory storage," Cell, vol. 147, no. 6, pp. 1369-1383, 2011.

[100] M. J. Bianchetta, T. T. Lam, S. N. Jones, and M. A. Morabito, "Cyclin-dependent kinase 5 regulates PSD-95 ubiquitination in neurons," The Journal of Neuroscience, vol. 31, no. 33, pp. 1202912035, 2011.

[101] S. H. Lee, L. Liu, Y. T. Wang, and M. Sheng, "Clathrin adaptor AP2 and NSF interact with overlapping sites of GluR2 and play distinct roles in AMPA receptor trafficking and hippocampal LTD," Neuron, vol. 36, no. 4, pp. 661-674, 2002.

[102] M. Joch, A. R. Ase, C. X.-Q. Chen et al., "Parkin-mediated monoubiquitination of the PDZ protein PICK1 regulates the activity of acid-sensing ion channels," Molecular Biology of the Cell, vol. 18, no. 8, pp. 3105-3118, 2007.

[103] A. Citri, G. Soler-Llavina, S. Bhattacharyya, and R. C. Malenka, " $N$-methyl-D-aspartate receptor- and metabotropic glutamate receptor-dependent long-term depression are differentially regulated by the ubiquitin-proteasome system," The European Journal of Neuroscience, vol. 30, no. 8, pp. 1443-1450, 2009.

[104] R. Fonseca, R. M. Vabulas, F. U. Hartl, T. Bonhoeffer, and U. V. Nägerl, "A balance of protein synthesis and proteasomedependent degradation determines the maintenance of LTP," Neuron, vol. 52, no. 2, pp. 239-245, 2006.

[105] L. Hou, M. D. Antion, D. Hu, C. M. Spencer, R. Paylor, and E. Klann, "Dynamic translational and proteasomal regulation of fragile X mental retardation protein controls mGluR-dependent long-term depression,” Neuron, vol. 51, no. 4, pp. 441-454, 2006. 
[106] A. Karpova, M. Mikhaylova, U. Thomas, T. Knöpfel, and T. Behnisch, "Involvement of protein synthesis and degradation in long-term potentiation of Schaffer collateral CA1 synapses," The Journal of Neuroscience, vol. 26, no. 18, pp. 4949-4955, 2006.

[107] V. C. Nalavadi, R. S. Muddashetty, C. Gross, and G. J. Bassell, "Dephosphorylation-induced ubiquitination and degradation of FMRP in dendrites: a role in immediate early mGluRstimulated translation," The Journal of Neuroscience, vol. 32, no. 8, pp. 2582-2587, 2012.

[108] J. Huang, Y. Ikeuchi, M. Malumbres, and A. Bonni, "A Cdh1APC/FMRP ubiquitin signaling link drives mGluR-dependent synaptic plasticity in the mammalian brain," Neuron, vol. 86, no. 3, pp. 726-739, 2015.

[109] M. Li, Y.-H. Shin, L. Hou et al., "The adaptor protein of the anaphase promoting complex Cdh1 is essential in maintaining replicative lifespan and in learning and memory," Nature Cell Biology, vol. 10, no. 9, pp. 1083-1089, 2008.

[110] D. Garcia-Arocena and P. J. Hagerman, "Advances in understanding the molecular basis of FXTAS," Human Molecular Genetics, vol. 19, no. 1, pp. R83-R89, 2010.

[111] C. Sellier, F. Rau, Y. Liu et al., "Sam68 sequestration and partial loss of function are associated with splicing alterations in FXTAS patients," The EMBO Journal, vol. 29, no. 7, pp. 1248$1261,2010$.

[112] T. Iijima, K. Wu, H. Witte et al., "SAM68 regulates neuronal activity-dependent alternative splicing of neurexin-1," Cell, vol. 147, no. 7, pp. 1601-1614, 2011.

[113] R. F. Berman, R. A. Buijsen, K. Usdin et al., "Mouse models of the fragile $\mathrm{X}$ premutation and fragile $\mathrm{X}$-associated tremor/ataxia syndrome," Journal of Neurodevelopmental Disorders, vol. 6, article 25, 2014.

[114] V. Beaumont, N. Zhong, R. Fletcher, R. C. Froemke, and R. S. Zucker, "Phosphorylation and local presynaptic protein synthesis in calcium- and calcineurin-dependent induction of crayfish long-term facilitation," Neuron, vol. 32, no. 3, pp. 489$501,2001$.

[115] A. Casadio, K. C. Martin, M. Giustetto et al., "A transient, neuron-wide form of CREB-mediated long-term facilitation can be stabilized at specific synapses by local protein synthesis," Cell, vol. 99, no. 2, pp. 221-237, 1999.

[116] H. H. Yin, M. I. Davis, J. A. Ronesi, and D. M. Lovinger, "The role of protein synthesis in striatal long-term depression," The Journal of Neuroscience, vol. 26, no. 46, pp. 11811-11820, 2006.

[117] A. M. Taylor, N. C. Berchtold, V. M. Perreau, C. H. Tu, N. Li Jeon, and C. W. Cotman, "Axonal mRNA in uninjured and regenerating cortical mammalian axons," The Journal of Neuroscience, vol. 29, no. 15, pp. 4697-4707, 2009.

[118] S. B. Christie, M. R. Akins, J. E. Schwob, and J. R. Fallon, “The FXG: a presynaptic Fragile X granule expressed in a subset of developing brain circuits," The Journal of Neuroscience, vol. 29, no. 5, pp. 1514-1524, 2009.

[119] M. Kundel, K. J. Jones, C. Y. Shin, and D. G. Wells, "Cytoplasmic polyadenylation element-binding protein regulates neurotrophin-3-dependent $\beta$-catenin mRNA translation in developing hippocampal neurons," The Journal of Neuroscience, vol. 29, no. 43, pp. 13630-13639, 2009.

[120] Y. Sasaki, K. Welshhans, Z. Wen et al., "Phosphorylation of zipcode binding protein 1 is required for brain-derived neurotrophic factor signaling of local $\beta$-actin synthesis and growth cone turning," The Journal of Neuroscience, vol. 30, no. 28, pp. 9349-9358, 2010.
[121] H. L. Zhang, T. Eom, Y. Oleynikov et al., "Neurotrophininduced transport of a beta-actin mRNP complex increases beta-actin levels and stimulates growth cone motility," Neuron, vol. 31, no. 2, pp. 261-275, 2001.

[122] M. Spillane, A. Ketschek, T. T. Merianda, J. L. Twiss, and G. Gallo, "Mitochondria coordinate sites of axon branching through localized intra-axonal protein synthesis," Cell Reports, vol. 5, no. 6, pp. 1564-1575, 2013.

[123] J. Baleriola, C. A. Walker, Y. Y. Jean et al., "Axonally synthesized ATF4 transmits a neurodegenerative signal across brain regions," Cell, vol. 158, no. 5, pp. 1159-1172, 2014.

[124] J. Blumenthal and I. Ginzburg, "Zinc as a translation regulator in neurons: implications for P-body aggregation," Journal of Cell Science, vol. 121, no. 19, pp. 3253-3260, 2008.

[125] J. Tcherkezian, P. A. Brittis, F. Thomas, P. P. Roux, and J. G. Flanagan, "Transmembrane receptor DCC associates with protein synthesis machinery and regulates translation," Cell, vol. 141, no. 4, pp. 632-644, 2010.

[126] E. Koenig, R. Martin, M. Titmus, and J. R. Sotelo-Silveira, "Cryptic peripheral ribosomal domains distributed intermittently along mammalian myelinated axons," The Journal of Neuroscience, vol. 20, no. 22, pp. 8390-8400, 2000.

[127] S. Viswanathan, M. E. Williams, E. B. Bloss et al., "Highperformance probes for light and electron microscopy," Nature Methods, vol. 12, no. 6, pp. 568-576, 2015.

[128] M. E. Tanenbaum, L. A. Gilbert, L. S. Qi, J. S. Weissman, and R. D. Vale, "A protein-tagging system for signal amplification in gene expression and fluorescence imaging," Cell, vol. 159, no. 3, pp. 635-646, 2014.

[129] O. Steward and P. M. Falk, "Polyribosomes under developing spine synapses: growth specializations of dendrites at sites of synaptogenesis," Journal of Neuroscience Research, vol. 13, no. 12, pp. $75-88,1985$.

[130] O. Steward and P. M. Falk, "Protein-synthetic machinery at postsynaptic sites during synaptogenesis: a quantitative study of the association between polyribosomes and developing synapses," The Journal of Neuroscience, vol. 6, no. 2, pp. 412-423, 1986.

[131] O. Steward and T. M. Reeves, "Protein-synthetic machinery beneath postsynaptic sites on CNS neurons: association between polyribosomes and other organelles at the synaptic site," The Journal of Neuroscience, vol. 8, no. 1, pp. 176-184, 1988.

[132] N. Maggio and A. Vlachos, "Synaptic plasticity at the interface of health and disease: new insights on the role of endoplasmic reticulum intracellular calcium stores," Neuroscience, vol. 281, pp. 135-146, 2014.

[133] M. S. Rook, M. Lu, and K. S. Kosik, “CaMKII $\alpha$ 3' untranslated region-directed mRNA translocation in living neurons: visualization by GFP linkage," The Journal of Neuroscience, vol. 20, no. 17, pp. 6385-6393, 2000.

[134] A. R. Buxbaum, Y. J. Yoon, R. H. Singer, and H. Y. Park, "Singlemolecule insights into mRNA dynamics in neurons," Trends in Cell Biology, vol. 25, no. 8, pp. 468-475, 2015.

[135] L. E. Ostroff, J. C. Fiala, B. Allwardt, and K. M. Harris, "Polyribosomes redistribute from dendritic shafts into spines with enlarged synapses during LTP in developing rat hippocampal slices," Neuron, vol. 35, no. 3, pp. 535-545, 2002.

[136] N. M. Sosanya, L. P. Cacheaux, E. R. Workman, F. Niere, N. I. Perrone-Bizzozero, and K. F. Raab-Graham, "Mammalian target of rapamycin (mTOR) tagging promotes dendritic branch variability through the capture of $\mathrm{Ca}^{2+} /$ calmodulin-dependent 
protein kinase II $\alpha$ (CaMKII $\alpha)$ mRNAs by the RNA-binding protein HuD," The Journal of Biological Chemistry, vol. 290, no. 26, pp. 16357-16371, 2015.

[137] A. Govindarajan, I. Israely, S.-Y. Huang, and S. Tonegawa, "The dendritic branch is the preferred integrative unit for protein synthesis-dependent LTP," Neuron, vol. 69, no. 1, pp. 132-146, 2011.

[138] H. Makino and R. Malinow, "Compartmentalized versus global synaptic plasticity on dendrites controlled by experience," Neuron, vol. 72, no. 6, pp. 1001-1011, 2011.

[139] S. H. Chang, H. S. Chung, N. K. Fontaine et al., "Mode division multiplexed optical transmission enabled by all-fiber mode multiplexer," Optics Express, vol. 22, no. 12, pp. 14229-14236, 2014.

[140] J. H. Lee, E. R. Daugharthy, J. Scheiman et al., "Highly multiplexed subcellular RNA sequencing in situ," Science, vol. 343, no. 6177, pp. 1360-1363, 2014.

[141] L. G. Tilney and M. S. Tilney, "The actin filament content of hair cells of the bird cochlea is nearly constant even though the length, width, and number of stereocilia vary depending on the hair cell location.", The Journal of Cell Biology, vol. 107, no. 6, pp. 2563-2574, 1988.

[142] J. F. Ross and M. Orlowski, "Growth-rate-dependent adjustment of ribosome function in chemostat-grown cells of the fungus Mucor racemosus," Journal of Bacteriology, vol. 149, no. 2, pp. 650-653, 1982.

[143] Z. B. Katz, A. L. Wells, H. Y. Park, B. Wu, S. M. Shenoy, and R. H. Singer, " $\beta$-actin mRNA compartmentalization enhances focal adhesion stability and directs cell migration," Genes and Development, vol. 26, no. 17, pp. 1885-1890, 2012.

[144] S. Saha, M. M. Mundia, F. Zhang et al., "Arginylation regulates intracellular actin polymer level by modulating actin properties and binding of capping and severing proteins," Molecular Biology of the Cell, vol. 21, no. 8, pp. 1350-1361, 2010.

[145] F. Zhang, S. Saha, S. A. Shabalina, and A. Kashina, "Differential arginylation of actin isoforms is regulated by coding sequencedependent degradation," Science, vol. 329, no. 5998, pp. 15341537, 2010.

[146] L. L. Orefice, E. G. Waterhouse, J. G. Partridge, R. R. Lalchandani, S. Vicini, and B. Xu, "Distinct roles for somatically and dendritically synthesized brain-derived neurotrophic factor in morphogenesis of dendritic spines," The Journal of Neuroscience, vol. 33, no. 28, pp. 11618-11632, 2013.

[147] D. C. Dieterich, J. J. L. Hodas, G. Gouzer et al., "In situ visualization and dynamics of newly synthesized proteins in rat hippocampal neurons," Nature Neuroscience, vol. 13, no. 7, pp. 897-905, 2010.

[148] K. M. Huber, S. M. Gallagher, S. T. Warren, and M. F. Bear, "Altered synaptic plasticity in a mouse model of fragile X mental retardation," Proceedings of the National Academy of Sciences of the United States of America, vol. 99, no. 11, pp. 7746-7750, 2002.

[149] J. M. Halstead, T. Lionnet, J. H. Wilbertz et al., "An RNA biosensor for imaging the first round of translation from single cells to living animals," Science, vol. 347, no. 6228, pp. 1367-1671, 2015. 

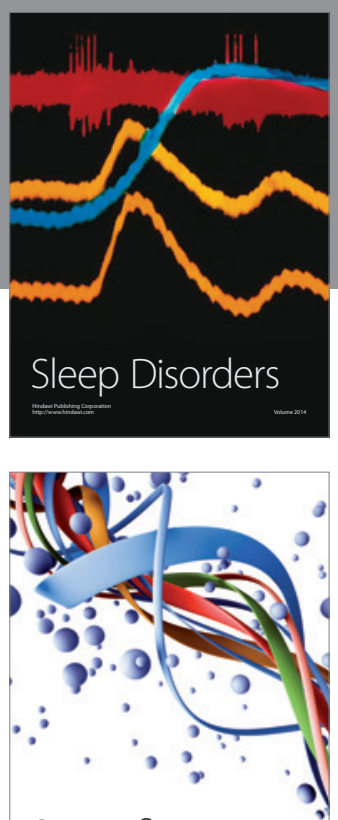

Scientifica
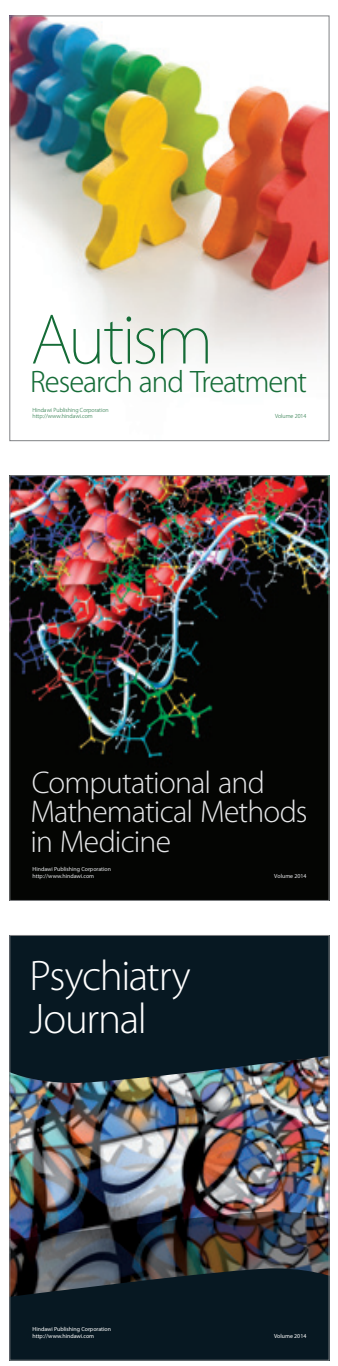
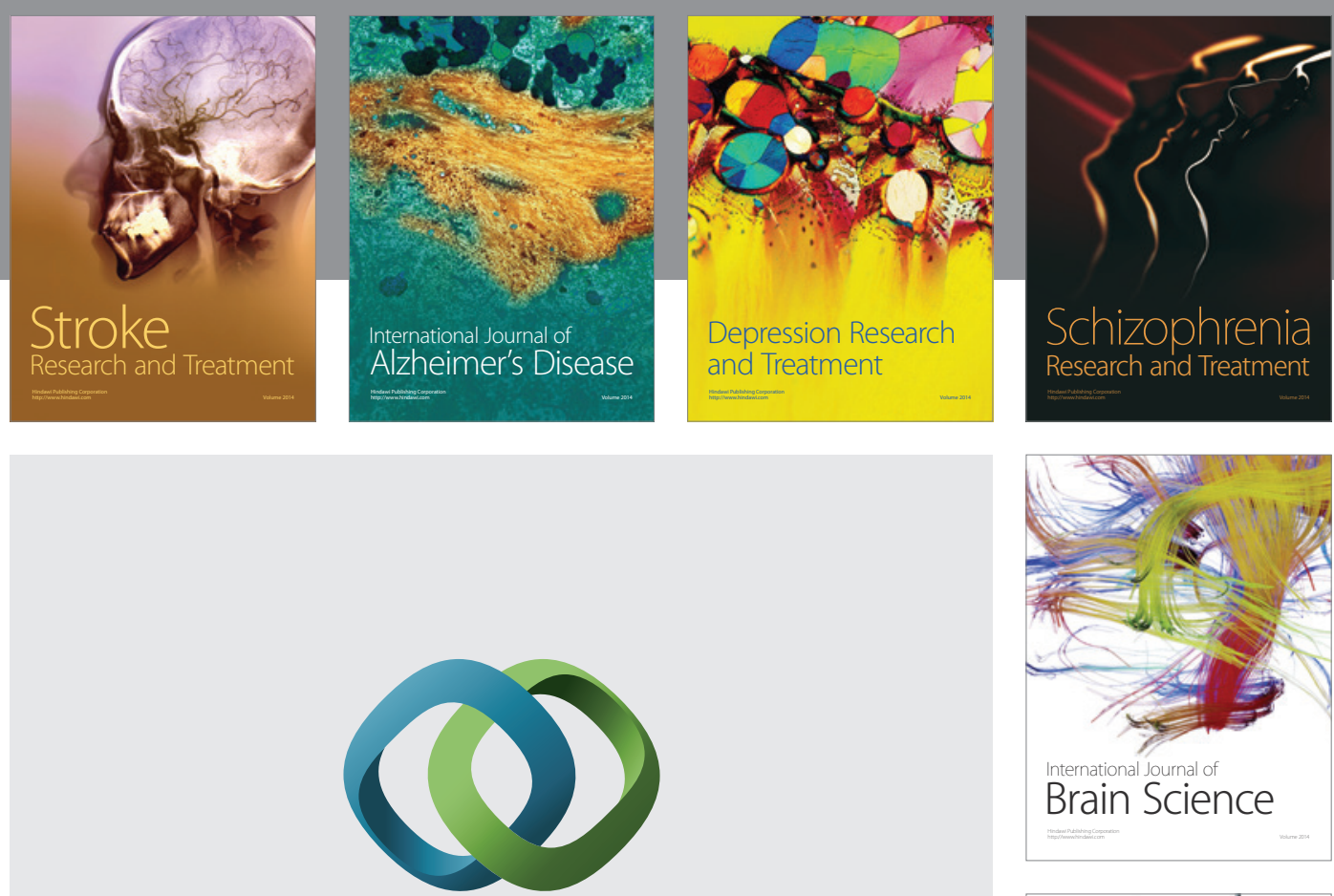

\section{Hindawi}

Submit your manuscripts at

http://www.hindawi.com
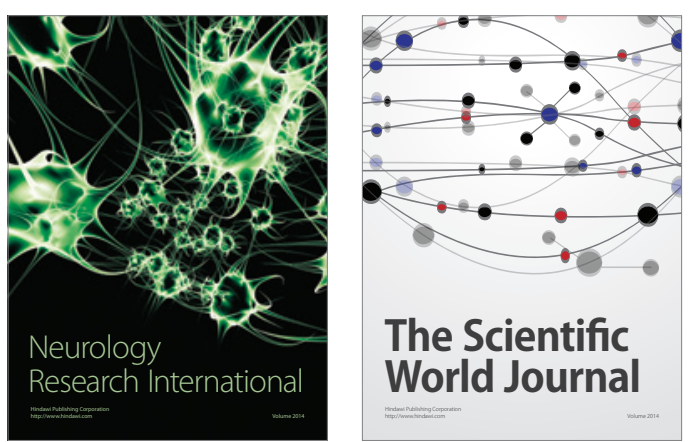

The Scientific World Journal

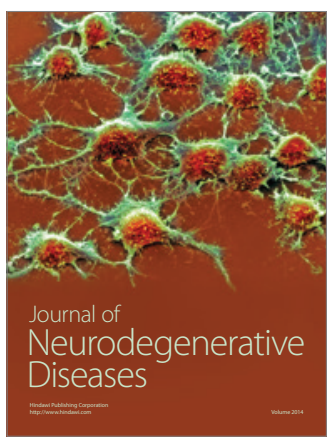

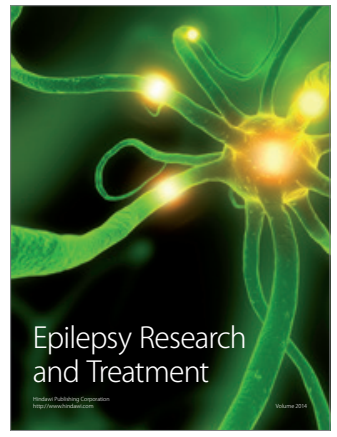

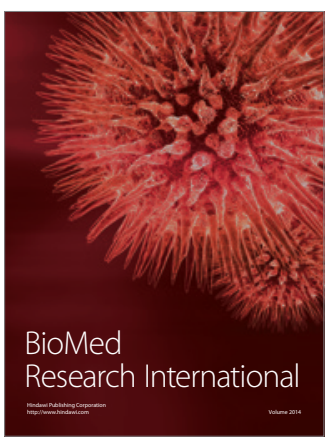

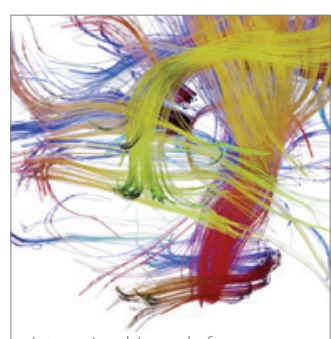

Brain Science

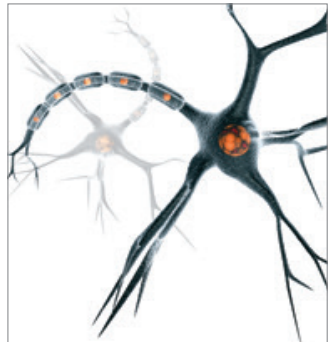

Neural Plasticity
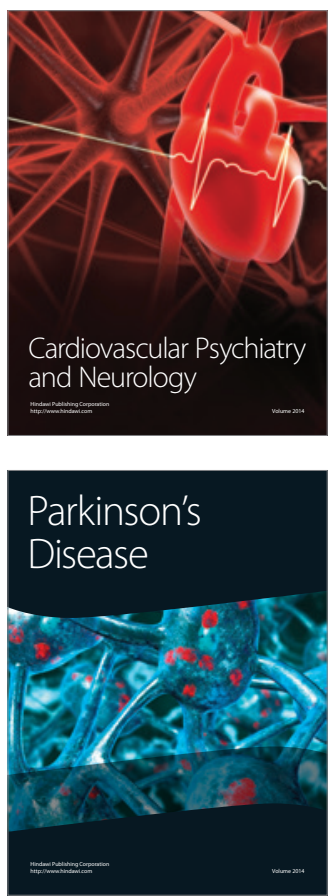